\author{
H. Irschik - M. Krommer • C. Marchioli • G. J. Weng
}

\title{
Editorial: Review and Perspective on the Soft Matter Modeling of Cellular Mechanobiology
}

Published online: 30 November 2017

(C) Springer-Verlag GmbH Austria, part of Springer Nature 2017

In this sixth article of the Review and Perspective in Mechanics series, we present the work of Professor Shaofan Li of the University of California at Berkeley and his team on the soft matter modeling of cellular mechanobiology. The focus here is on cell mechanics, with a special reference to cell contact, cell adhesion, mechanosensing, and motility. The authors adopted the concept of soft matter to model the behavior of biological cells. In this process the interactions among cells, and between cell and extracellular matrix, are examined in great detail. Such interactions have profound implications on the spreading and migration of cells, development of cell cultures, modeling of cancer cells, and muscle growth and wound healing. The review covers many contemporary experimental observations, mathematical modeling, and computational schemes. It is divided into nine distinct sections. Following a broad Introduction, the biological background of the cell membrane and its adhesion to the extracellular matrix are outlined in Section 2. In Section 3, the development of active gel hydrodynamics for actin filaments is presented. It Section 4, the computational statistical model for the crosslink networks of actin filaments is introduced, and in Section 5, the tensegrity model of the cytoskeleton for applications to cell orientation and migration is given. The recent study of cell contact and cell adhesions with the effect of surface tension is reviewed in Section 6, and modeling of cellular mechanosensing is discussed in Section 7. In Section 8, computational simulations by Monte Carlo method, molecular dynamics method, finite element method, and mesh-free method are presented. The article concludes in Section 9 on the future challenges and opportunities of cell modeling and simulations. With significant depth and breadth, this review provides a unique perspective on the modern subject of cell mechanics.

H. Irschik

Linz, Austria

E-mail: irschik@mechatronik.uni-linz.ac.at

M. Krommer

Vienna, Austria

C. Marchioli

Udine, Italy

G. J. Weng $(\varangle)$

New Brunswick, NJ, USA

E-mail: gjweng@soe.rutgers.edu 